\title{
Effect of Different Concentration of Growth Regulators on in vitro Culture of Rice
}

\author{
Yamini Bhanot* and Vivek Shrivastava \\ Department of Microbiology, Guru Jambheshwar University of Science and Technology, \\ Hisar, India \\ *Corresponding author
}

\begin{tabular}{l} 
Ke y w o r d s \\
Oryza sativa, \\
Embryogenic \\
callus, \\
Regeneration, \\
Somaclonal \\
variation, Tissue \\
culture \\
\hline Article Info \\
$\begin{array}{l}\text { Accepted: } \\
10 \text { November } 2020 \\
\text { Available Online: } \\
\text { 10 December } 2020\end{array}$ \\
\hline
\end{tabular}

\section{A B S T R A C T}

A laboratory experiment was conducted in the laboratory of Biotechnology at Dayanand College, Hisar in which seeds of rice cv. MR219were used for regeneration of whole plants. Seeds were soaked overnight in sterilized water for 24 hours to soften and imbibe the seed for recovery of embryos. Seed were dehusked with the forceps and collected in the Petri dish or washed for 3-4 times with sterilized distilled water and again washed for one minute in distilled water. After one minute seeds transfer in $75 \%$ ethanol for one minute and again sterilized in 30\% sodium hypo chloride for 20 minutes. Finally thoroughly washed in sterile water for at least three times under the aseptic conditions and used as the source of material for explants. Mainly, MS (Murashigeand skoog) media was used in the tissue culture Operation. The $\mathrm{pH}$ was adjusted to 5.8.Best results of root generations were obtained by using MS media with IBA. The best results of shoot regeneration were obtained by using MS media with BAP and IAA.

\section{Introduction}

Rice is the staple food of many countries throughout the world. Thus, it is very important to ensure the constant availability of this crop. However, conventional propagation methods have several disadvantages such as the unavailability of large-scale true-to-type planting materials and vulnerability to environmental changes. In vitro regeneration has an advantage over conventional propagation method in producing disease free plants at high multiplication rate. The Malaysian indica rice MR219 is currently the most popular rice variety grown in Malaysia since its release in 2001. A few advantageous characteristics of this indica rice variety include short maturation period of only 105-111 days, fairly tall but strong culms and resistance to blast 
and bacterial leaf blight. Regeneration studies have been established for rice using various sources of explants including mature seeds, shoot segments, embryos and axillary shoot segments. In previous studies, rice was regenerated for genetic transformation purposes using explants such as, Shoot apical meristem (SAM), coleoptile, mature embryo or shoot and root tips. However, to date, there are no reports of an ideal protocol that bypasses the intermediate callus phase for the in vitro regeneration of indica rice, Meristem tissue as an explant has the ability to regenerate shoots without the intermediate callus development in the ideal concentration and combination of PGRs. Shoot formation requires sub culturing processes that are laborious and time consuming. Meristem tissue ensures genetic stability and minimizes somaclonal variations by avoiding adventitious organogenesis. Also, juvenile tissue is advantageous because it contains most actively dividing cells; it is highly responsive in tissue culture medium and has high regenerative ability compared to tissue obtained from mature sources. Hence, the present study uses SAM obtained from juvenile stage (Plumuleof 4 - day old germinating rice seedling) as an explant for plant regeneration. Apart for the type of explant, PGRs also determine the effectiveness of an in - vitro regeneration protocol. The type and concentration of PGRs shows significant variability in in vitro regeneration of various species and cultivars. According to the culture medium and PGRs determine the optimum response of an explant. It is especially vital to regenerate indica rice genotypes since these varieties are principal food source for most tropical regions in the world.

Tissue culture techniques have become necessary for the production of the transgenic rice plants (Peng et al., 1992), hybrids (Mariam et al., 1996) and for the recovery of germplasm when seed availability is limited.
These methods are based on adventitious shoot culture (Shahsavari, 2011) and somatic embryogenesis (Amarasinghe, 2009) which resulted into genetic variations in rice cultivars (Mannan et al., 2013). Using exogenous 2, 4-D treatment and yeast extract callus induction od stem nodes as explant was carried out by Furushashi and Yantazawa (1964). This was further extended by (Yamada et al., 1967) using IAA and 2, 4-D with cytokinins. The most effective growth regulator of callus induction in rice is $2,4-\mathrm{D}$ without cytokinin treatment. Micropropagation protocols have been established for rice cultivars using as explants like as mature seeds (Ullah et al., 2007), shoot segments (Verma et al., 2011), embryos (Ali et al., 2004, Evangelista et al., 2009), anthers (Khatunet al., 2010) which produced regenerated plantlets. Fifteen rice cultivars of rice were screened for induction of callus as well as subsequent regeneration of plantlets through plant tissue culture (Hertke and Lo“rz, 1989). Similarly, 500 cultivars of rice were comprehensively studied for the induction of callus as well as regeneration of plantlets by Kamia et al., (1988). It was also reported that an individual genotype of rice plays a significant role in the induction of callus and regeneration of plantlets (Hoque and Mansfield, 2004, Islam et al., 2005).

Therefore, the present study was undertaken to regenerate whole Malaysian indica rice cv. MR219 plants from SAM, in optimized PGRs without the intermediate callus phase. Also, in this study we evaluate the effects of different PGRs towards the in vitro regeneration of MR219 rice from SAM.

\section{Materials and Methods}

\section{Plant material (explants)}

Seeds of rice were used for regeneration of whole plant. Rice outer husk is dehusked and collect all the clean seeds in petridish. 


\section{Sterilization of glassware's media and other instruments}

Glass wares were thoroughly washed with detergent or tap water and dried in hot air oven at $140 \mathrm{C}$. Forceps were dipped in alcohol and wrapped by aluminium foil and place it into the oven for sterilization. The working surface of laminar air flow was thoroughly cleaned with alcohol before starting the operation.

\section{Sterilization of explant}

Seed were dehusked with the forceps and collect all seed in the Petri dish or washed for 3-4 times sterilized distilled water and again wash for $1 \mathrm{~min}$ in distilled water. After one min. seeds transfer in $75 \%$ ethanol for $1 \mathrm{~min}$. and again sterilized in $30 \%$ sodium hypo chloride for $20 \mathrm{~min}$. Finally thoroughly wash in sterile water for at least three times under the aseptic conditions and used as the source of material for explants.

\section{Preparation of stock solutions}

At the time of media preparation, it is practically not possible to weigh each of the ingredients needed in the medium. Hence, for the sake of convenience, concentrated stock solutions of basal MS medium containing different ingredients were prepared (Table 1) in double distilled water and stored in glass bottles in refrigerator at $5^{\circ} \mathrm{C}$ temperature.

\section{Preparation of culture media}

After addition of various kinds of adjuvant (after bringing stock solutions to room temperature) to the MS basal medium, the $\mathrm{pH}$ of medium was adjusted to 5.8 using $0.1 \mathrm{~N}$ $\mathrm{HCl}$. The final volume adjusted and $8 \mathrm{gm} / \mathrm{l}$ agar-agar was added to the medium and then hormones in respective treatments were added to the media and then dispensed in suitable container i.e. culture bottles (Table 2).
Autoclaving was done using horizontal steam sterilizer at $121^{\circ} \mathrm{c}$ and $1.5 \mathrm{lbs} / \mathrm{cm} 2$ pressure for $20 \mathrm{~min}$. After sterilization, the medium was allowed to cool down then medium were poured in culture bottles and allowed to solidify at room temperature and stored in dust proof room for at least 3 days before use to check for any contamination.

\section{Inoculation}

Surface sterilized seeds were inoculated in media under aseptic environment provided by Laminar Air Flow. Surface of the chamber was washed with $70 \%$ ethanol before starting operation. The cotton bud of conical flask was removed which contained MS media. The seeds of explant were picked from petridish with the help of sterilized forceps and inoculate the explant seed into the conical flask which contained MS media (Plate 1). The neck of conical flask was sterilized on spirit lamp and then put the cotton bud on neck of the conical flask. To minimize chance of infection the instruments were dipped in disinfectant after every operation.

\section{Shoot regeneration}

After 7 days, the embryos and the embryonic axis were isolated aseptically from preconditioned explants and were culture on MS medium containing different concentration of BA and kinetin with or without NAA. All culture media were supplemented with $3 \%$ sucrose, $8 \mathrm{ml} / 1$ agar. Explants were subculture to the same medium after 4 and 7 weeks on the same medium devoid of activated after 10 weeks of culture.

\section{Rooting}

After the culture, the regenerated shoots were rooted in MS medium containing different concentration of IBA (indole - 3 - butyric acids). After 4 weeks of rooting the rooting plantlets were transferred to plasmodesmata. 


\section{Results and Discussion}

\section{Effect of media on shoot regeneration}

Present investigation showed that the number of days required for shoot initiation was influenced due to different levels of BAP and constant IAA (Table 3 and Plate 2). Shoot regeneration was recorded in explants in all generation media, but $100 \%$ response shoot per explants were significantly different on both explants, BAP. IAA is responsible for the formation of shoots. The same results were observed by Dahanayaka et al., (2012) the highest shoot induction was recorded on MS basal medium with $2.5 \mathrm{mg} / 12,4-\mathrm{D}$ and
$0.1 \mathrm{mg} / \mathrm{1}$ BAP for selected Sri Lankan traditional rice varieties.

\section{Effect of media on rooting}

Results of root growth in media supplemented with IBA presented in Table 4. Root formation was recorded in explants in different generation gives different results. IBA effect the rooting in different generations. The quantity of IBA gives different results. The root number was influenced due to different levels of BA in combination with constant NAA was also studied by Bakshi et al., (2020) in Bamboo.

Table.1 Preparation of stock solution

\begin{tabular}{|c|c|c|c|c|}
\hline Sr. No. & Stock solution & Compound & $\begin{array}{l}\text { Amount } \\
\text { Per liter }\end{array}$ & $\begin{array}{c}\text { Total } \\
\text { Volume }\end{array}$ \\
\hline 1. & Major Salt & $\begin{array}{l}\mathrm{NH}_{4} \mathrm{NO}_{3} \\
\mathrm{Cacl}_{2} \\
\mathrm{KNO}_{3} \\
\mathrm{MgSO}_{4} \\
\mathrm{KH}_{2} \mathrm{PO}_{4}\end{array}$ & $\begin{array}{l}16.5 \mathrm{gm} \\
4.4 \mathrm{gm} \\
19 \mathrm{gm} \\
3.7 \mathrm{gm} \\
1.7 \mathrm{gm}\end{array}$ & $\begin{array}{l}500 \mathrm{ml} \\
(20 \mathrm{X})\end{array}$ \\
\hline 2. & Minor Salt 1 & $\begin{array}{l}\mathrm{H}_{3} \mathrm{PO}_{4} \\
\mathrm{MnSO}_{4} \cdot 4 \mathrm{H}_{2} \mathrm{O} \\
\mathrm{ZnSO}_{4} \cdot 7 \mathrm{H}_{2} \mathrm{O} \\
\mathrm{Kl} \\
\mathrm{Na}_{2} \mathrm{MoO}_{4} \cdot 2 \mathrm{H}_{2} \mathrm{O}\end{array}$ & $\begin{array}{c}0.62 \mathrm{gm} \\
2.230 \mathrm{gm} \\
0.860 \mathrm{gm} \\
0.083 \mathrm{gm} \\
0.25 \mathrm{gm}\end{array}$ & $\begin{array}{l}100 \mathrm{ml} \\
(200 \mathrm{X})\end{array}$ \\
\hline 3. & Minor Salt 2 & $\begin{array}{l}\mathrm{CuSO}_{4} \cdot 5 \mathrm{H}_{2} \mathrm{O} \\
\mathrm{CaCL}_{2} \cdot \mathrm{C} \mathrm{H}_{2} \mathrm{O}\end{array}$ & $\begin{array}{l}0.025 \mathrm{gm} \\
0.025 \mathrm{gm}\end{array}$ & $\begin{array}{l}200 \mathrm{ml} \\
(200 \mathrm{X})\end{array}$ \\
\hline 4. & $\begin{array}{l}\text { Chelating } \\
\text { Agents }\end{array}$ & $\begin{array}{l}\mathrm{Na}_{2} \text { EDTA } \\
\mathrm{FeSO}_{4} 7 \mathrm{H}_{2} \mathrm{O}\end{array}$ & $\begin{array}{l}0.373 \mathrm{gm} \\
0.278 \mathrm{gm}\end{array}$ & $\begin{array}{l}200 \mathrm{ml} \\
(200 \mathrm{X})\end{array}$ \\
\hline 5. & Vitamins & $\begin{array}{l}\text { Myoniositol } \\
\text { Nicotinic Acid } \\
\text { Thymine HCL } \\
\text { Glycine } \\
\text { Pyridoxine HCL }\end{array}$ & $\begin{array}{c}10000 \mathrm{mg} / \mathrm{L} \\
50 \mathrm{mg} / \mathrm{L} \\
10 \mathrm{mg} / \mathrm{L} \\
200 \mathrm{mg} / \mathrm{L} \\
50 \mathrm{mg} / \mathrm{L}\end{array}$ & $\begin{array}{c}\begin{array}{c}100 \mathrm{mg} / 100 \mathrm{ml} \\
\text { Freshly } \\
\text { prepared } 100 \mathrm{X}\end{array} \\
100 \mathrm{X} \\
100 \mathrm{X} \\
100 \mathrm{X}\end{array}$ \\
\hline
\end{tabular}


Table.2 Preparation of culture media from stock solution

\begin{tabular}{|l|l|c|c|}
\hline Sr. No. & Stock Solution & $\begin{array}{c}\text { Total volume of } \\
\text { stock solution(ml) }\end{array}$ & $\begin{array}{c}\text { Volume for 11/t of } \\
\text { media }\end{array}$ \\
\hline 1. & Major salt & 500 & $50 \mathrm{ml} / 1$ \\
\hline $\mathbf{2 .}$ & Minor Salt 1 & 100 & $5.0 \mathrm{ml} / 1$ \\
\hline $\mathbf{3 .}$ & Minor salt 2 & 200 & $5.0 \mathrm{ml} / 1$ \\
\hline $\mathbf{4 .}$ & Chelating agent & 200 & $5.0 \mathrm{ml} / 1$ \\
\hline $\mathbf{5 .}$ & Vitamins & 100 & $10 \mathrm{~g} / 1000 \mathrm{ml}$ \\
\hline $\mathbf{( a )}$ & Myoinositol & & Freshly prepared \\
\hline (b) & Nicotinic acid & $25 \mathrm{mg} / \mathrm{ml}$ & $0.5 \mathrm{ml} / 1$ \\
\hline (c) & Thymine & $25 \mathrm{mg} / 25 \mathrm{ml}$ & $0.1 \mathrm{ml} / 1$ \\
\hline (d) & Glycine & $25 \mathrm{mg} / 1$ & $2.0 \mathrm{ml} / 1$ \\
\hline (e) & Pyridoxine & $25 \mathrm{gm} / 5 \mathrm{ml}$ & $0.5 \mathrm{ml} / 1$ \\
\hline
\end{tabular}

Agar $=0.5 \mathrm{gm} / \mathrm{lt}$, Sucrose $=30 \mathrm{gm} / \mathrm{lt}$,

Table.3 Effect of different concentration of growth regulators on shoot regeneration

\begin{tabular}{|c|c|c|c|c|c|c|}
\hline Media & BAP & NAA & Kinetin & IAA & Result & Days \\
\hline MS 1. & $25 \mu 1$ & --- & --- & $150 \mu 1$ & $\begin{array}{l}\text { Forth day } \\
\text { Contamination } \\
\text { occurs }\end{array}$ & $\begin{array}{l}1^{\text {st }} \text { three days shoot } \\
\text { arise } \& \text { than } \\
\text { contamination occurs. }\end{array}$ \\
\hline MS 2. & --- & $10 \mu l$ & $20 \mu 1$ & --- & $20 \%$ response & $\begin{array}{l}1^{\text {st }} \text { two days shoot arise } \\
\& \text { than } 3^{\text {rd }} \text { day } \\
\text { contamination occurs. }\end{array}$ \\
\hline MS 3. & $50 \mu 1$ & --- & --- & --- & $60 \%$ response & $\begin{array}{l}1^{\text {st }} \text { four days shoot arise } \\
\& \text { than growth stop. No } \\
\text { contamination occurs }\end{array}$ \\
\hline MS 4. & $50 \mu 1$ & --- & --- & $10 \mu 1$ & $30 \%$ response & $\begin{array}{l}1^{\text {st }} \text { four days shoot arise } \\
\& \text { than growth stop. No } \\
\text { contamination occurs }\end{array}$ \\
\hline MS 5. & $60 \mu 1$ & $10 \mu 1$ & --- & --- & $80 \%$ response & $1^{\text {st }}$ six days shoot arise. \\
\hline
\end{tabular}


Table.4 Effect of different concentration of growth regulators on shoot regeneration

\begin{tabular}{|l|l|l|l|}
\hline Sr.No. & Media & IBA(mg/L) & Results \\
\hline 1. & MS(1.1) & 1.5 & $2.5 \mathrm{~cm}$ (fast growth) \\
\hline 2. & MS(1.2) & 2.0 & $\begin{array}{l}2.0 \mathrm{~cm}(\text { slow } \\
\text { growth) }\end{array}$ \\
\hline
\end{tabular}

Plate.1 Inoculation of seed

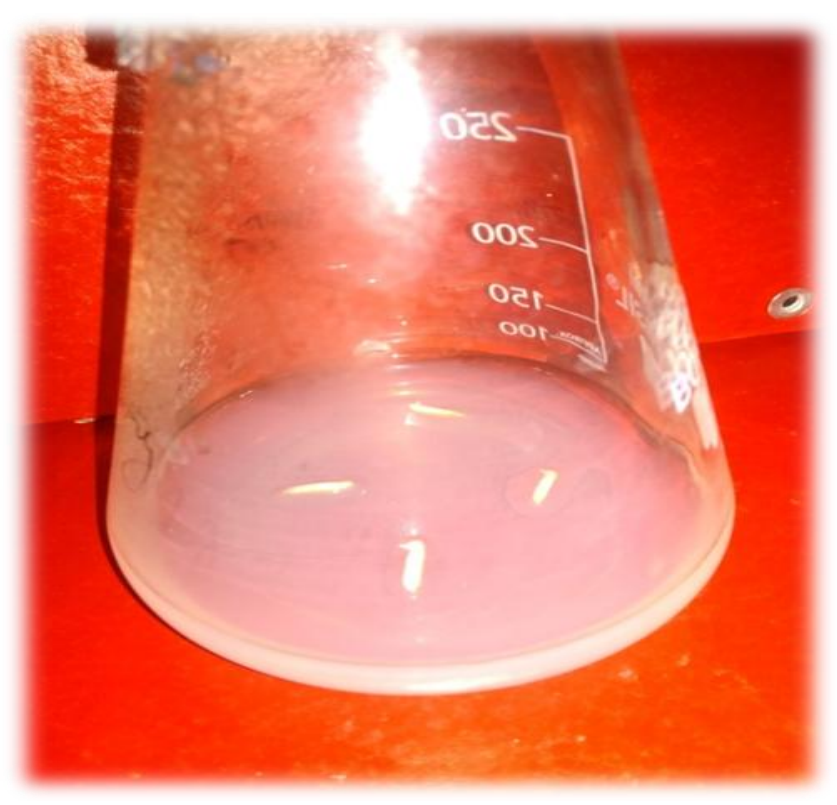

Plate.2 Formation of shoot

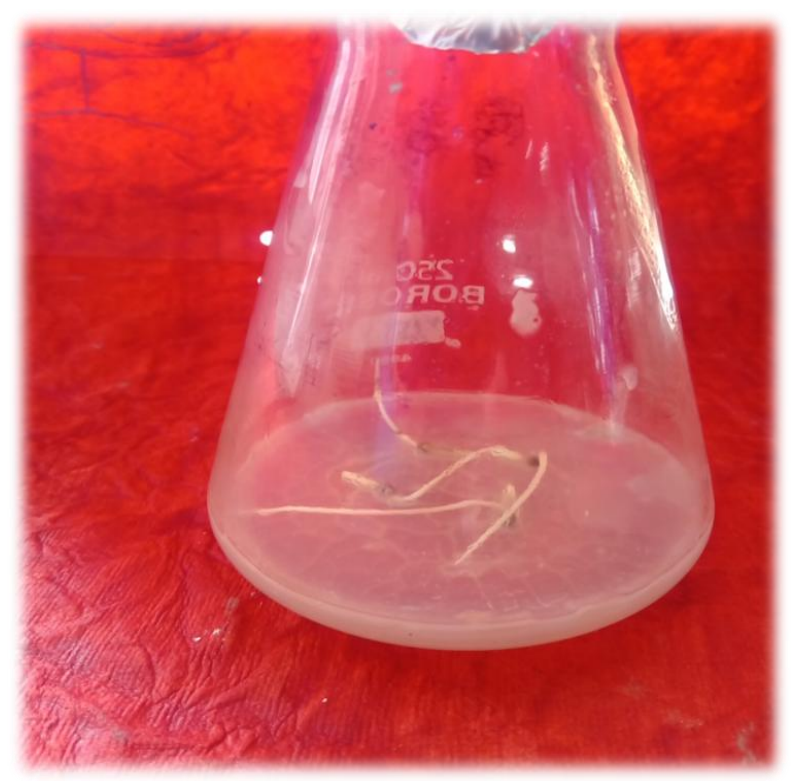




\section{Acknowledgment}

The authors gratefully acknowledge the Faculty of Biotechnology, Dayanand College, Hisarwho permitted to carry out this experiment by using all the facilities available Dayanand College, Hisar, Haryana

\section{References}

Ali, S., Qing-zhong, X. and Xian-yin, Z.2004. Assessment of various factors involved in the tissue culture system of rice. Rice Sci. 11:345-349.

Amarasinghe, A. A. Y. 2009. Effects of copper sulphate and cobalt chloride on in vitro performances of traditional indica rice (Oryza sativa L.) varieties in Sri Lanka. J Agric Sci. 4: 132-141.

Dahanayake, N. and Ranawake, A. L.2012. Shoot and plantlet regeneration ability of selected Sri Lankan Traditional rice cultivars (Oryza sativa L.) in caryopses culture. Tropical Agricultural Research Extension, 15(2): 15-18.

Evangelista FC, Aldemita RR, Ungson LB. (2009) Callusing and regeneration potential of rice (Oryza sativa L.) genotypes towards the development for salt tolerance. Philippine J Sci.,

Evangelista, F. C., Aldemita, R. R. and Ungson, L. B. 2009. Callusing and regeneration potential of rice (Oryza sativa L.) genotypes towards the development for salt tolerance. Philippine J Sci, 138:169-176.

Furuhashi, K. and Yatazuva, M. 1964. Indefinitely growing rice callus in tissue culture. Kagaku 34: 623.

Hertke, S. and Lo“rz, H. 1989. Somatic embryogenesis and plant regeneration from various indica rice (Oryza sativa) genotype. J Genet Breed, 43:205-214

Hoque, E. H. and Mansfield, J.W. 2004. Effect of genotype and explants age on callus induction and subsequent plant regeneration from root derived callus of rice genotypes. Plant Cell Tiss Org Cult. 78(3): 217-223.

Islam, M. M., Ahmed, M. and Mahalder, D. 2005. In vitro callus induction and plant regeneration in seed explants of rice (Oryza sativa L.). Res J Agric Biol Sci. 1:72-75.

Kamia, M., Kamanaka, H. andOono, K. 1988. Intervarietal variations insomatic embryogenesis in rice (Oryza sativa L.). Bull Nat Inst Aerobiol Resour. 4:12715.

Khatun, R., Shahinul Islam, S. M. and Bari Miah, M. A. 2010. Studies on plant regeneration efficiency through in vitro micropropagation and anther culture of twenty five rice cultivars in Bangladesh. J Appl Sci Res. 6:1705-1711.

Mannan, M. A., Sarker, T. C., Akhter, M. T., Kabir, A. H. andAlam, M. F. 2013. Indirect plant regeneration in aromatic rice (Oryza sativa L.) var. 'Kalijira' and 'Chinigura'. Acta Agric Slovenica, 101-2:231-238.

Mariam, A. L., Zakri, A. H., Mahani, M. C. and Normah, M. N. 1996. Interspecific hybridization of cultivated rice, Oryza sativa L. with the wildrice $O$. minuta Presl. TheorAppl Genet. 93:664-671.

Peng, H., Kononowicz, H. and Hodges, T. K. 1992. Transgenic indica riceplants. Theor Appl Genet. 83:855-863

Bakshi, P. N., Khetre, S. S. and Talekar, B.K. 2020. Effect of Different Concentrations of BA with Constant NAA on Shoot Proliferation of Bamboo (Dendrocalamus asper). Int. J.Curr.Microbiol.App.Sci. 9(10): 1-10. doi:

https://doi.org/10.20546/ijcmas.2020.91 0.001

Shahsavari, E. 2011. Impact of tryptophan and glutamine on the tissue culture of upland rice. Plant Soil Environ. 57:7-10 Ullah, H., Ullah, I., Jadoon, S. A. and Rashid, 
H. 2007. Tissue culture techniques for callus induction in rice. Sarhad J Agricult.23:81-86

Verma, D., Joshi, R., Shukla, A. and Kumar, P. 2011. Protocol for in vitro somatic embryogenesis and regeneration of rice
(Oryza sativa L.). Indian Journal of Experimental Biology, 49:958-963 Yamada, Y., Tanaka, K. and Takahashi, E. 1967. Callus induction in rice, Oryza sativa L. Proc. Jap. Acad. 43: 156-160.

\section{How to cite this article:}

Yamini Bhanot and Vivek Shrivastava. 2020. Effect of Different Concentration of Growth Regulators on in vitro Culture of Rice. Int.J.Curr.Microbiol.App.Sci. 9(12): 1150-1157.

doi: https://doi.org/10.20546/ijcmas.2020.912.139 